\title{
COVID-19, Social Media, and Policy: Suggestions for Canada's Health Messaging Response
}

\section{Parham Elmi ${ }^{1}$}

${ }^{1}$ Simon Fraser University, Burnaby, BC, Canada

\section{Correspondence}

Parham Elmi

Email: parham_elmi@sfu.ca

Publication Date

September 4, 2021

MJM $2022(20) 4$

https://doi.org/10.26443/mjm.v20i1.862

\section{McGill}

\section{Journal of Medicine}

www.mjmmed.com

\section{(c) (i) (2) (2)}

This work is licensed under a Creative Commons BY-NC-SA 4.0 International License.

\section{ABSTRACT}

COVID-19 has impacted the lives of many Canadians physically, emotionally, and financially. This commentary focuses on suggestions on how to use social media platforms to target Canadians to promote public COVID-19 related health messaging. Policy strategies that limit the use of algorithms for social media in an effort to eliminate opinion silos and provide users with a more well-rounded view of current events are explored.

\section{KEYWORDS}

Social Media, COVID-19, Pandemic, Health Messaging, Policy

\section{1 | INTRODUCTION}

The COVID-19 pandemic has forced many to adapt to new circumstances. For students and teachers, this has meant learning how to effectively utilize technology as their sole method of interaction. (1) For those employed prior to the pandemic: being laid off with little idea of what their financial future holds. (2) For those fortunate enough to still have their jobs: how to work from home. (3) Finally, for those making decisions at a public health and governing level: how to deal with the pandemic from a health, financial, and political standpoint, and how to disseminate public health messages effectively to their citizens. These are just a few examples of the mental, physical, and financial impacts of the pandemic. $(2,4)$ Given the morbidity and mortality risks of COVID-19, public messaging reaching Canadians must provide accurate and reliable health messages that are in line with expert opinion. $(4,5)$ This commentary reviews various ways in which health messages can be conveyed, 
and proposes new health messaging strategies that can be utilized to effectively reach Canadians.

\section{2 | HEALTH MESSAGING}

Health messaging can take multiple forms. It includes top-down dissemination of health information from physicians and public health officials as well as word-of-mouth communication between family members, friends, and colleagues. It is important that all public health messages align and are consistent to avoid confusion. This is particularly true given the serious risks associated with contracting and spreading COVID-19. (5) Consistent, targeted, and appropriate health messaging can help individuals become familiar with and develop an affinity for its contents when repeatedly exposed to it via the "mere exposure effect." (6) Unfortunately, the mere exposure effect can also increase the tendency for individuals to believe information that is incorrect or false. (7) This is an issue as "fake news" has been shown to spread significantly faster than accurate news on social media. (7)

Given that Internet users between the ages of 16-64 reported using social media for an average of 2.5 hours per day during 2020, it is important to discuss this in detail. (8) Fake news detracts from important public health messaging in two ways: it encourages apathy in the population, and it propagates conspiracy theories. $(7,9,10)$ For example, many people believe that COVID-19 only affects the elderly as they are at much higher risk of fatality from exposure to the virus. (11) Although mortality rates from COVID-19 are low amongst younger individuals, adverse complications due to morbidity remain relevant within this cohort. (12) When modeling high quality years of life lost if infected by COVID-19 (using chronic fatigue syndrome as a proxy for COVID19's disability), one study found that individuals in their 20 's can lose up to six years depending on the severity of their COVID-19 symptoms and gender. (12) Health messaging that mentions more relevant morbidity risk from COVID-19 may help combat apathy towards public health regulations in younger cohorts.
The rapid transmission of "fake news" through social media combined with COVID-19's negative impact on mental health may have promoted the adoption of conspiracy theories and movements such as the "anti-mask" movement. $(4,13,14)$ Chen et al. surveyed healthcare workers and found that belief in COVID-19 conspiracy theories was correlated to poorer mental health. (13) These types of movements can counter accurate public health messaging and can further spread inaccurate information through both from the ground up (e.g., to family and friends) or top-down (e.g., creating a viral social media post). Disseminating accurate health information not only requires targeting the appropriate audience with the appropriate medium and message, but also combatting the spread of false information on the web and beyond. To help health expert opinion battle false news online, creation of engaging material in abundance is necessary. (9) Working together with individuals who are well-versed in creating this sort of content allows experts to disseminate this information in a way that is digestible to the masses.

\section{3 | COLLABORATION WITH IN- FLUENCERS}

Research has demonstrated that influential leaders within groups can promote positive health behaviours. $(15,16)$ Campbell et al., showed that training schoolaged peer leaders - voted as leaders by classmates on the negative impacts of smoking decreased the number of individuals who engaged in smoking compared to groups without these leaders. (15) Kelly et al. showed similar significant findings when popular homosexual men were selected as peer leaders and trained on HIV prevention strategies such as using condoms and avoiding unprotected anal sex. (16) They found that individuals who had access to these peer leaders demonstrated a significant increase in condom use during anal intercourse, and a significant decrease in the frequency of unprotected anal intercourse. (16)

Collaboration with social media influencers may provide a cost-effective and targeted strategy to spread 
health messaging, especially to the younger demographic. $(17,18)$ A survey in 2020 showed that more than $90 \%$ of Canadian adults with Internet access also have access to one or more social media accounts. (18) Younger individuals (18-24) have the highest reported social media usage, making it an ideal medium to target younger cohorts. (18) A 2017 survey conducted on more than 4,000 individuals indicated that most users who followed influencers favoured those with a "lifestyle" brand, and that one third bought a service or product that an influencer was promoting. (19) Given the content that lifestyle brands produce, working with this group of influencers allows public health messages to be disseminated naturally to a lay audience.

Surveys in Canada have shown that younger people are less likely to abide by public health messaging. (17) Promotion of public health messaging may be able to encourage improved public safety if influencers collaborate with health regions, but are given sufficient autonomy to offer authentic and personalized content as these factors have been shown to foster trust. (19) The Fraser Health Region in British Columbia recruited volunteers between the ages of 20-29 to share ideas and social media content as "health influencers" to help stop the spread of COVID-19. (20) Recruiting willing individuals to create and share content can aid public health messaging, but collaborating with larger influential content creators who already have a dedicated following should also be considered. Different influencers and social media platforms target different users, and thus various combinations could be used to encapsulate a variety of demographics. (18) Creation of incentives and challenges to promote public health messaging should also be considered to encourage discourse on public health messages.

\section{I SOCIAL MEDIA CONTESTS AND CHALLENGES}

With many Canadians active on social media, using best practices to reach the highest number of users as cheaply as possible would help to disseminate public health messaging. (18) One issue with social media platforms is that they have varying levels of organic reach, or the ability to reach their followers without paying the company to promote their posts. (21) There are ways, however, to maximize the organic reach of a post. Promoting user engagement with a post is one method on Facebook. (21) For example, by offering an incentive like a draw for a free product to a certain number of individuals who engage with a post by "liking", "commenting", and "following" the respective public health agency on their social media feed. Contests like this serve two purposes: they increase exposure and followers to proper public health accounts, and they increase the organic reach of each post to share important public health information. When an individual has engaged with a post on their feed, their network is also able to see that activity on their feed, which quickly allows these messages to reach a wider audience across different social media platforms. When creating messaging for these contests it is important to include topics that encourage dialogue and comments on the comments of others such as: "comment below something that you are doing to keep up your mental health." This strategy will garner more engagement on posts and serves as another method to increase exposure to accurate public health channels and information. (21) Combining these methods with the right amount of paid sponsorship will help posts reach more individuals and do so cost-effectively. All contest metrics can be tracked (i.e., engagement, costs, etc.) and modulated from one contest to another to compare different messaging, demographics, and cost efficiency.

Another effective strategy is the use of health messaging challenges to engage with friends and spread health messaging. These challenges create a personalized, fun, and user-generated method to share health messaging. One of the most notable health messaging challenges was the Amyotrophic Lateral Sclerosis (ALS) ice bucket challenge (IBC) in 2014. This challenge went viral and led to a 35-fold increase in donations for ALS charities compared to the previous year. (22) Furthermore, Twitter posts during this same time period showed an increased use of the hashtags icebucketchal- 
lenge and ALS also experienced a much greater usage, whereas the use of multiple sclerosis (MS) hashtags remained fairly consistent. (22) Creating health challenges similar to the IBC promotes conversations regarding the contest and its message. (19)

Creating similar challenges related to COVID-19 complications relevant to younger individuals (such as the fatigue) may improve engagement with public health messaging. $(11,12)$ For example, one challenge can be asking users to do the max amount of body weight squats they can in one minute, while also counting back from a random number by 7 . Participants would do this once at the start of the day and once after staying up for 4 hours longer than they normally would. The difference in performance could serve as a proxy for how fatigue complications from COVID-19 would feel. The competitive nature of this challenge would also encourage participation from other social media users. (12)

This challenge can teach individuals directly, vicariously through watching peers on social media, and also through discussions where peers communicate their experiences with one another. As described, health messaging contests and challenges can aid in targeting Canadians with public health messaging, but ultimately policy change is required to make a more lasting impact.

\section{5 | POLICY RECOMMENDATIONS AND SUGGESTIONS FOR SOCIAL MEDIA}

Since most social media sites that Canadians use generate revenue through advertisement, showing content that is in line with a user's viewpoints is in the social media companies' best interests, but may distort a user's reality. $(18,21)$ As mentioned, COVID-19 has had a negative impact on the mental health of many, and with mental distress being associated with conspiracy theory adoption, which can counter to accurate public health messaging. $(4,13,14)$ Although social media may be very useful to promote public health messaging, the limitations of this strategy must be considered. There are many issues with tailoring content to make it relevant for the end user. With regards to health messaging, tailored content may distort reality for end-users and encourage confirmation bias. When an individual only sees one point of view, they may miss an opportunity to see appropriate public health messaging. Considering that individuals who are seeing the same content have similar preferences, the majority of comments can add social validity to further the individual's belief in a particular view (e.g., that COVID-19 is a hoax). (23) The second issue is the creation of information and opinion silos where individuals are encouraged to consume media deemed relevant to them by social media algorithms. The reason why this tailored delivery of content is dangerous for the end user can be explained through the Self Determination Theory (SDT). This theory asserts that an individual's motivation can be affected by three pillars: competence, relatedness, and autonomy. (24) When an individual is constantly exposed to news on social media that opposes mainstream media, they may feel a sense of competency as they may feel like they know the "truth," but the majority are misinformed. When individuals choose a post to engage with and see others commenting in agreement with their beliefs, it would strengthen their feeling of autonomy and relatedness. This example illustrates why individuals may believe in conspiracy theories or false health information that run counter to public health messaging.

For these reasons, public health agencies should work with social media companies to ensure algorithms maximize exposure to a wide variety of perspectives. Creating a system that verifies the accounts of public health experts accounts may also aid users in distinguishing what sources are reputable on these platforms. As a long-term consideration, policies that limit or eliminate the use of algorithms to deliver relevant content to social media users should be implemented to further battle misinformation and promote health messaging. These policies will allow citizens to obtain more accurate information, see both sides of an argument, and help promote public health messaging. This type of policy could also assist in other avenues, such as elections at the municipal, provincial, and international level. As an initial consideration, public health officials should 
encourage compassion and understanding between all Canadians as everyone has different content tailored through their social media feed. Through thoughtful discussion with peers who have opposing views, opinion silos can be broken down, which may encourage individuals to consider another point of view. Beyond policy, education on privacy and how social media platforms deliver content should be prioritized to ensure Canadians know how the algorithm of these platforms currently works.

\section{6 | CONCLUSION}

The COVID-19 pandemic has radically changed the way that Canadians communicate and consume information. The better individuals comprehend and comply with health messaging, the sooner we can return to pre-pandemic life. Both macro and micro strategies should be utilized to effectively target Canadians, focusing specifically on social media contests, collaboration with influencers, and policy to deter information silos and misinformation on social media platforms. By utilizing these strategies, public health will gain an advantage to better spread accurate public health messages to each individual and improve their chances of winning the battle against misinformation. The traditional lives Canadians experienced pre-pandemic have been engulfed into a new and everchanging digital world. As our society progresses through these strange and unprecedented times, it is vital that our public health messaging can traverse alongside our remodeling nation in order to inform, educate, and promote health to as many Canadians as possible.

\section{7 | ACKNOWLEDGEMENTS}

I would like to thank the McGill Journal of Medicine team and those assigned to peer-review my article for their time, support, and feedback. I would also like to thank Colin Fowler and Samer Rihani for their insightful comments on this manuscript.

\section{REFERENCES}

1. Besser A, Flett GL, Zeigler-Hill V. Adaptability to a sudden transition to online learning during the COVID-19 pandemic: Understanding the challenges for students. Scholarsh Teach Learn Psychol [Internet]. 2020 Oct 19;n/a(Advance online publication):1-22. Available from: http://doi.apa.org/getdoi.cfm?doi=10.1037/stl0000198

2. Lemieux T, Milligan K, Schirle T, Skuterud M. Initial impacts of the COVID-19 pandemic on the Canadian labour market. Can Public Policy [Internet]. 2020;46(1):S55-65. Available from: https://doi.org/10.3138/cpp.2020-049

3. Gottlieb C, Grobovšek J, Poschke M. Working from home across countries. Covid Econ. 2020;(8):71-91.

4. Cullen W, Gulati G, Kelly BD. Mental health in the COVID-19 pandemic. QJM [Internet]. 2020;113(5):311-2. Available from: https://doi.org/10.1093/qjmed/hcaa110

5. Liotta EM, Batra A, Clark JR, Shlobin NA, Hoffman SC, Orban ZS, et al. Frequent neurologic manifestations and encephalopathy-associated morbidity in Covid-19 patients. Ann Clin Transl Neurol [Internet]. 2020;7(11):2221-30. Available from: https://doi.org/10.1002/acn3.51210

6. Zajonc RB. Mere exposure: A gateway to the subliminal. Curr Dir Psychol Sci [Internet]. 2001;10(6):224-8. Available from: https://doi.org/10.1111/1467-8721.00154

7. Vosoughi S, Roy D, Aral S. The spread of true and false news online. Science (80- ) [Internet]. 2018 Mar 9;359(6380):1146 LP - 1151. Available from: http://science.sciencemag.org/content/359/6380/1146.abstract 8. Kemp S (We AS. Digital 2020 Global Overview Report [Internet]. We Are Social and Hootsuite. 2020 [cited 2021 Feb 15]. Available from: https://wearesocial.com/blog/2021/01/digital-2021the-latest-insights-into-the-state-of-digital

9. Naeem S Bin, Bhatti R, Khan A. An exploration of how fake news is taking over social media and putting public health at risk. Heal Inf Libr J [Internet]. 2020 Jul 12;n/a(n/a). Available from: https://doi.org/10.1111/hir.12320

10. Ognyanova K, Lazer D, Robertson RE, Wilson C. Misinformation in action: Fake news exposure is linked to lower trust in media, higher trust in government when your side is in power. Harvard Kennedy Sch Misinformation Rev [Internet]. 2020;1(4):1-19. Available from: https://doi.org/10.37016/mr-2020-024

11. Xiang $X$, Lu X, Halavanau A, Xue J, Sun $Y$, Lai PHL, et al. Modern Senicide in the Face of a Pandemic: An Examination of Public Discourse and Sentiment About Older Adults and COVID-19 Using Machine Learning. J Gerontol B Psychol Sci Soc Sci [Internet]. 2021;76(4):e190-200. Available from: https://doi.org/10.1093/geronb/gbaa128

12. Smith MP. Estimating the total morbidity burden of COVID19. medRxiv [Internet]. 2021 Jan 1;2021.04.20.21255818. Available from: http://medrxiv.org/content/early/2021/04/24/ 2021.04.20.21255818.abstract 
13. Chen X, Zhang SX, Jahanshahi AA, Alvarez-Risco A, Dai H, Li $\mathrm{J}$, et al. Belief in a COVID-19 conspiracy theory as a predictor of mental health and well-being of health care workers in Ecuador: Cross-sectional survey study. JMIR Public Heal Surveill [Internet]. 2020;6(3):1-7. Available from: https://doi.org/10.2196/20737

14. Allington D, Duffy B, Wessely S, Dhavan N, Rubin J. Health-protective behaviour social media usage and conspiracy belief during the COVID-19 public health emergency. Psychol Med [Internet]. 2020/06/09. 2020;1-7. Available from: https://doi.org/10.1017/S003329172000224X

15. Campbell R, Starkey F, Holliday J, Audrey S, Bloor M, ParryLangdon $\mathrm{N}$, et al. An informal school-based peer-led intervention for smoking prevention in adolescence (ASSIST): a cluster randomised trial. Lancet [Internet]. 2008;371(9624):1595-602. Available from: https://doi.org/10.1016/S0140-6736(08)60692-3

16. Kelly JA, Murphy DA, Sikkema KJ, McAuliffe TL, Roffman RA, Solomon LJ, et al. Randomised, controlled, community-level HIVprevention intervention for sexual-risk behaviour among homosexual men in US cities. Lancet [Internet]. 1997;350(9090):1500-5. Available from: https://doi.org/10.1016/S0140-6736(97)07439-4 17. Brankston G, Merkley E, Fisman DN, Tuite AR, Poljak Z, Loewen $\mathrm{PJ}$, et al. Socio-demographic disparities in knowledge, practices, and ability to comply with COVID-19 public health measures in Canada. Can J Public Heal [Internet]. 2021;112(3):363-75. Available from: https://doi.org/10.17269/s41997-021-00501-y

18. Gruzd A (Ryerson U-O 0000-0003-2366-5163, Mai P (Ryerson U-O 0000-0002-6950-1220. The State of Social Media In Canada 2020. Ryerson Univ Soc Media Lab [Internet]. 2020;1-18. Available from: https://dx.doi.org/10.2139/ssrn.3651206

19. Olapic. Why Consumers Follow, Listen to, and Trust Influencers [Internet]. 2017 [cited 2021 Feb 7]. Available from: https://www.olapic.com/resources/consumers-follow-listentrust-influencers ${ }_{a}$ rticle/

20. Fraser Health recruiting volunteer health influencers [Internet]. 2020 [cited 2021 Jan 1]. Available from: https://www.fraserhealth.ca/news/2020/Aug/fraser-health-

recruiting-volunteer-health-influencers

21. Cooper $P$ (hootsuite). How the Facebook Algorithm Works in 2021 and How to Make it Work for You [Internet]. Hootsuite. 2021 [cited 2021 Feb 15]. Available from: https://blog.hootsuite.com/facebook-algorithm/

22. Koohy $\mathrm{H}$, Koohy B. A lesson from the ice bucket challenge: Using social networks to publicize science. Front Genet [Internet]. 2014;5(DEC):1-3. Available from: https://doi.org/10.3389/fgene.2014.00430

23. Cyca M. What is Social Proof and How to Use It In Your Marketing Strategy [Internet]. Hootsuite. 2019 [cited 2020 Feb 15]. Available from: https://blog.hootsuite.com/social-proof/

24. Ryan R, Deci E. Self-Determination Theory and the Facilitation of Intrinsic Motivation, Social Development, and Well-Being. Am Psychol. 2000 Feb 1;55:68-78. 